\title{
The correlation between tribological properties of nanostructure TiN coatings and deposition process parameters in PACVD system
}

Mehdi Raoufi $^{1}$

\author{
${ }^{1}$ Department of Materials Science and Engineering, Arak University, Arak, Iran \\ e-mail: Raoufi@iust.ac.ir
}

\begin{abstract}
Titanium base coatings are being used extensively for improving wear characteristics at the surface of different parts. Titanium nitride was deposited by Plasma Assisted Chemical Vapor Deposition (PACVD) techniques with purpose improve interface with substrate, as this can increase wearing of the entire part in spite of desirable wear behavior of TiN. Samples from H13 steel were prepared and they experienced plasma nitriding (PN) prior to TiN deposition. TiN coatings were deposited in different conditions of temperature $\left(475,500\right.$ and $\left.525^{\circ} \mathrm{C}\right)$ and duty cycle $(33,40$ and $50 \%)$. Topographic studies were preceded by Atomic Force Microscope (AFM). Surface hardness was evaluated using Vickers's micro-hardness test. In order to study the wear behavior, pin-on-disc test was chosen which included examining the sample's resistance against pins from steel and tungsten carbide-cobalt. Based on the results obtained it can be observed that increasing the deposition temperature from 475 to $525^{\circ} \mathrm{C}$ will lead to higher values of hardness, thus the obtained weight loss from samples decreased from 2.1 to $0 \mathrm{mg}$. In addition to that, with increasing the duty cycle of system from 33 to $50 \%$, weight loss of the TiN coating has increased from 0 to $2 \mathrm{mg}$ due to an increase in the value of surface roughness.
\end{abstract}

Keywords: PACVD; Duty cycle; TiN coatings; Wear

\section{INTRODUCTION}

Titanium nitride thin films have a versatile combination of physical and chemical properties that have found increasing interest for applications such as corrosion protection [1, 2], diffusion barriers [3], and wear resistance [4]. Because of its excellent wear-resistant properties, titanium nitride has attracted considerable research and it is, in tribological terms, the first largely explored hard, thin coating. However, these coatings normally exhibit high friction and are not suitable for low-friction sliding applications. It has been reported in earlier papers [5-8] that TiN coatings deposited by PACVD showing low chlorine content, which is incorporated as TiCl4 is used as chloride precursor in the PACVD process, are well suited to reduce the friction coefficient in ball-on-disc testing against different counterpart materials to extremely low values below 0.2 . The drop of the friction coefficient to these low values after a running-in period is attributed to the formation of an interfacial lubricant film on top of the TiN coating in combination with humidity [5-6, 8].

There is a variation in the contact mechanism and the wear process in sliding contacts between titanium nitride and steel depending on contact parameters such as geometry, speed, load and roughness. The roughness of surface coatings is attributed to the deposition process parameters such as temperature and duty cycle [9]. Therefore, there is a dialectic relation between the wear mechanism and the deposition process parameters. A little is known about the detailed correlation tribological behavior of the nanostructure TiN coatings and the effect of deposition temperature and duty cycle that is deposited by plasma assisted chemical vapor deposition (PACVD) [9].

The tribological performance and properties of titanium nitride are sensitive to the processing conditions and microstructure of the material. The main purpose of this paper is to investigate the structure and tribological behaviors with particular reference to the morphology of surfaces, and establish correlation between tribological properties of nanostructure TiN coatings and deposition process parameters in PACVD system. 


\section{MATERIALS AND METHODS}

AISI H13 for use in the manufacture of extruded forms was the substrate used in this study which its' chemical composition was obtained by Optical Emission Spectrometer as shown in Table 1. The samples in the cylindrical form (diameter: $20 \mathrm{~mm}$ and height: $10 \mathrm{~mm}$ ) were quenched and tempered. The hardness of the prepared samples was $48 \mathrm{HRC}$. They were polished and cleaned in alcohol solution.

Table 1: Chemical composition of hot work steel H13

\begin{tabular}{lllllllllll}
\hline Element & $\mathrm{C}$ & $\mathrm{Si}$ & $\mathrm{Mn}$ & $\mathrm{Cr}$ & $\mathrm{Mo}$ & $\mathrm{V}$ & $\mathrm{Co}$ & $\mathrm{Ni}$ & $\mathrm{W}$ \\
\hline Weight percent & 0.38 & 1.05 & 0.4 & 5.1 & 1.25 & 0.4 & Trace & Trace & Trace \\
\hline
\end{tabular}

Prior to TiN deposition, the substrates were exposed to a combined sputtering and nitriding pretreatments. The substrate temperature was kept constant at $525{ }^{\circ} \mathrm{C}$ to avoid exceeding the tempering temperature of the hot work steel. The processing parameters for plasma nitriding are listed in Table 2.

Table 2: Plasma nitriding parameters

\begin{tabular}{ll}
\hline Voltage $(\mathrm{V})$ & 550 to 610 \\
\hline Drum Pressure (Pascal) & 150 \\
Deposition Temperature $\left({ }^{\circ} \mathrm{C}\right)$ & $475,500,525$ \\
$\mathrm{~N} 2 / \mathrm{N} 2+\mathrm{H} 2$ & 0.22 \\
Duty Cycle (\%) & $33,40,50$ \\
Deposition Time (hr) & 4 \\
\hline
\end{tabular}

The plasma nitriding (PN) and PACVD TiN deposition were conducted in the same industrial set plant. The cylindrical vacuum chamber, which is $500 \mathrm{~mm}$ in diameter and $700 \mathrm{~mm}$ in height, can be heated with an auxiliary heating system, the temperature of which is controlled by a thermocouple and kept constant at $475^{\circ} \mathrm{C}$. The substrate is put directly on the charging plate, which is also used as the cathode of the system. The surrounding wall of the chamber is used as the anode of the system and the potential earth. The flow of a mixture of gases consisting of $\mathrm{H} 2, \mathrm{~N} 2$, Ar and TiCl4 (flow rates 1.6, 0.25, 0.05, $0.1 \mathrm{Nl} / \mathrm{min}$, respectively) is measured and controlled by mass-flow controllers. TiCl4 is transported to the chamber through an amount of carrier gas $(\mathrm{H} 2)$ flowing through the TiCl4 tank, with the temperature kept constant at $40{ }^{\circ} \mathrm{C}$. To carry out this task, various duty cycles $(33,40$ and 50\%) have been applied. The discharge voltage was varied from 550 to $610 \mathrm{~V}$. The deposition time and pressure were kept at 4 hours, $2 \mathrm{mbar}$, respectively.

The surface topography was characterized using WITec model alpha300-A Atomic Force Microscopy (AFM) along with the calculating software. The scanning area for all samples was $5 \mu \mathrm{m} \times 5 \mu \mathrm{m}$. The Vickers hardness of the TiN coatings was measured using a micro-hardness testing machine, within the loading range of 50 to $100 \mathrm{~g}$; five micro-hardness tests were performed for each sample to obtain the average values of the hardness. Studying the wear behavior and measuring the friction coefficient of samples, were accomplished with pin-on-disc technique including pins from 100Cr6 steel (DIN 1.3505) and tungsten carbide-cobalt (WC$\mathrm{Co}$ ). In this test the applied load on pin selected as $10 \mathrm{~N}$ and the pin whirred on disc samples while temperature and humidity contents were $27^{\circ} \mathrm{C}$ and $34 \%$, respectively. Finally, the weight loss of samples was reported as the main criterion for wear resistance.

\section{RESULTS AND DISCUSSION}

\subsection{The effect of duty cycle}

Figure 1 depicts coefficients of friction for the deposited sample at $525^{\circ} \mathrm{C}$ temperature and $33 \%$ duty cycle being worn against pins made from steel and tungsten carbide-cobalt. 


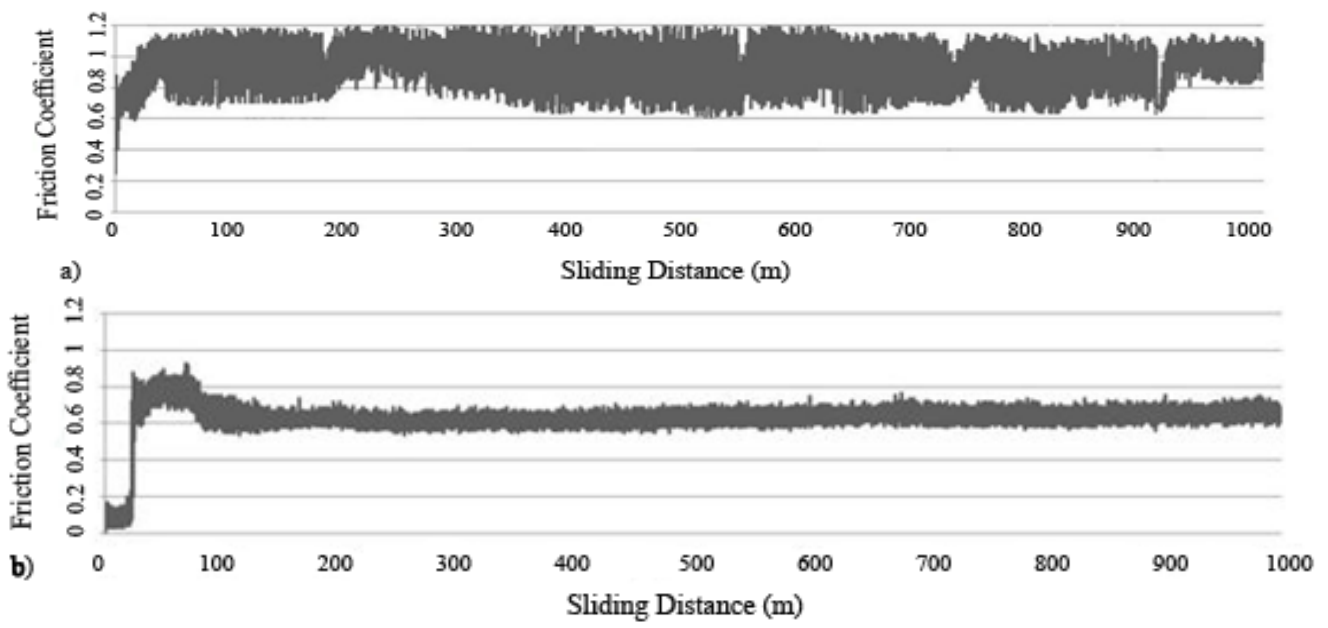

Figure 1: The diagram of the friction coefficient for a $\mathrm{PN}+\mathrm{TiN}$ sample deposited at $525^{\circ} \mathrm{C}$ with a $33 \%$ duty cycle against: (a) a steel pin and (b) a tungsten carbide pin.

As can be seen, friction coefficient using the steel pin was 0.95 approximately and since this value has changed about \pm 0.05 , we have not presented the friction coefficient curve for $40 \%$ and $50 \%$ duty cycles. In addition, due to high amplitudes of oscillations in the curve during wearing against the steel pin, comparison of these diagrams during different duty cycles will be accomplished with significant errors. The same phenomenon was observed using tungsten carbide (WC) pin. As shown in Figurelb, the friction coefficient is 0.65 approximately and by changing the duty cycle, very little variation in the value has been reported.

One important point evident from analyzing these diagrams is the prominent difference between them. Wearing against the steel pin has produced a broader curve for friction coefficient with higher values which can be attributed to lower hardness of the steel pin. It is believed that with supplying the required energy, further involvements and adhesions in the surface between pin and disk will be occurred. This leads to higher forces needed to maintain movement of the pin on the disk which will increase the friction coefficient. Large oscillation amplitudes of the friction coefficient diagram are also justified by this reason. When small adhesion is formed between the two surfaces the diagram of friction coefficient increases in order to provide the required force to separate the surfaces from each other [10]. Just when this force is provided and the pin is set free, friction coefficient will decrease. This situation along the wearing path can cause micro-cracks in the worn grooves which is not a good sign for the wear behavior. On the other hand, using the WC pin can cause little involvement between the surfaces (two ceramic surface), which results both smaller friction coefficients and limited oscillations. Here no sign of local adhesion will be present and most of the wear will be abrasive [10, 11].

In Figure 2 weight loss in the samples and their relevant rubbing steel pins with same geometry has been summarized. A significant difference is also evident between the disk samples and their pins which are reasonable due to the difference between their hardness numbers. As can be seen, the weight loss increases relatively with the duty cycle which is attributed to the lower hardness and higher surface roughness for the deposited samples in longer duty cycles. 


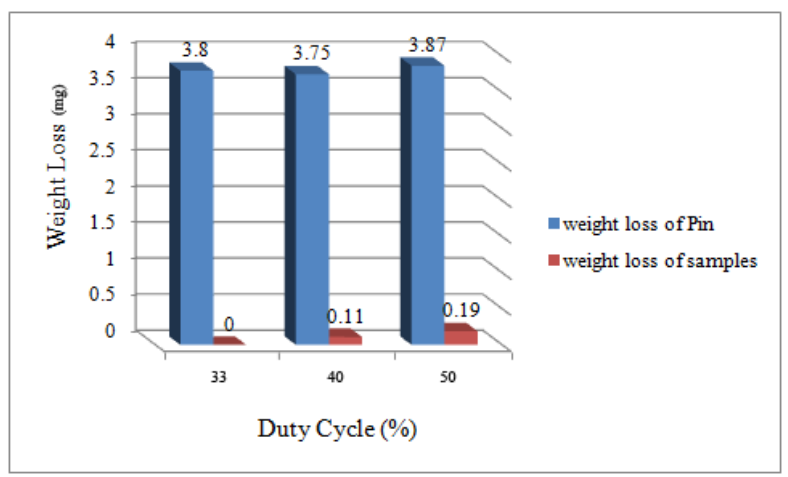

Figure 2: The weight loss in the samples and their respected rubbing steel pins for different duty cycles.

It can be seen from Figure 3 that the hardness values decrease with increasing the duty cycle, which can be attributed to larger particle sizes of TiN coating because they enlarge during longer duty cycles. Because the hardness inversely relates to the wear [13], higher weight loss of deposited samples in $50 \%$ duty cycle was expected.

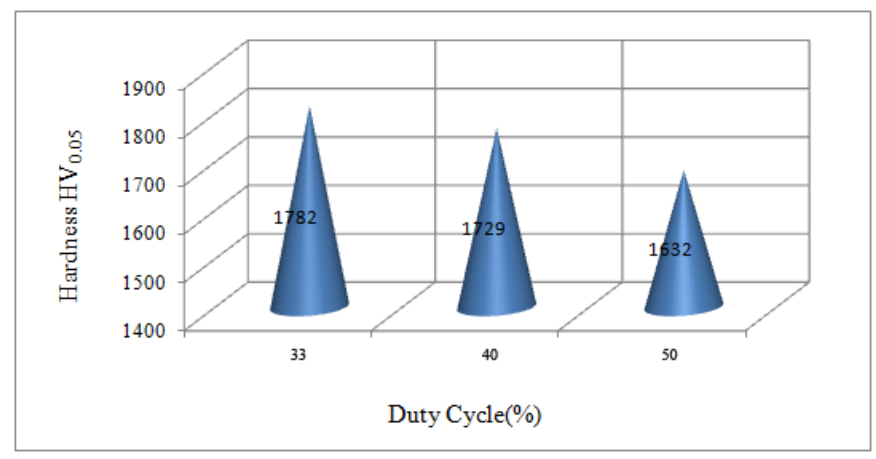

Figure 3: The hardness of TiN coatings for various duty cycles deposited on the $\mathrm{H} 13$ at deposition temperature of $475^{\circ} \mathrm{C}$.

Figure 4 depicts 3D images of AFM from coating surface. As evident from this, the roughness content has raised for longer duty cycles. When the surface roughness increases, chips will have more probability to be scratched from the surface of the disk sample.

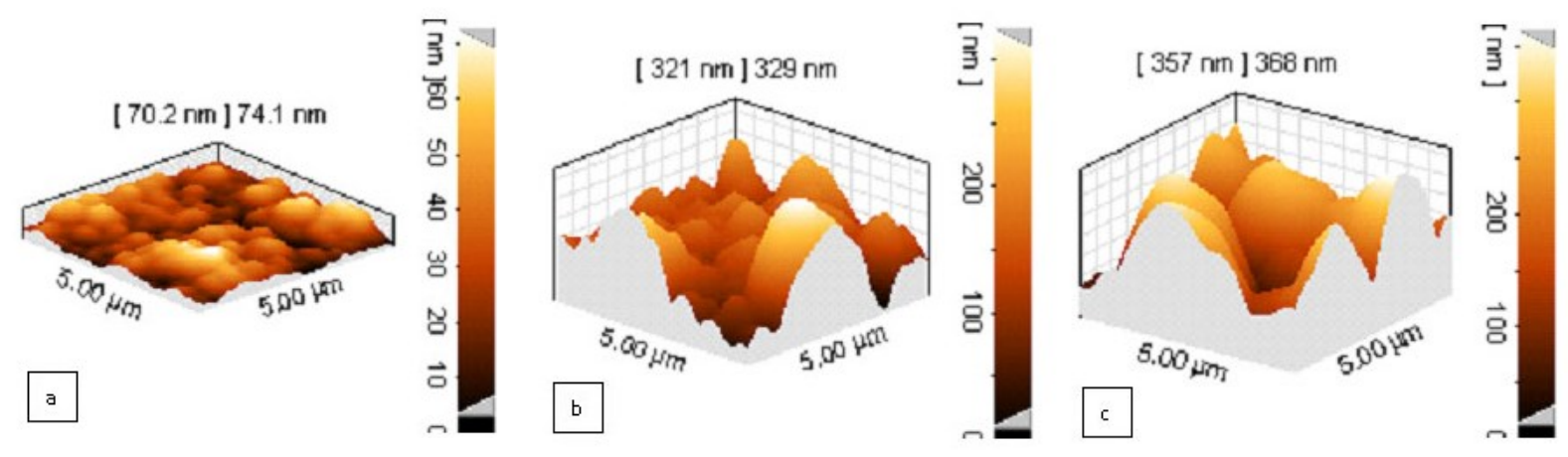

Figure 4: 3D presentation of an AFM image of TiN coatings for different duty cycles: a) 33\%, b) 40\%, and c) $50 \%$ deposited on the $\mathrm{H} 13$ at a deposition temperature of $475^{\circ} \mathrm{C}$; scanning area $5 \mu \mathrm{m} \times 5 \mu \mathrm{m}$.

Noteworthy here is that the weight loss for the deposited sample in $33 \%$ duty cycle was reported as null. Although, it doesn't mean that the weight loss is zero at all, some little weight loss will be present since the scratched chips can be caught in the available grooves of the disk sample. The weight loss from the sample due to wear can be neutralized with the weight gain of it due to entrapment of pin chips, so the weight 
will be same before and after the wearing.

The weight loss from the samples and WS pins with same geometry rubbing them has been presented in Figure 5. It can be seen that the weight loss has increased dramatically in comparison to the previous experiment while the weight loss of the pins was far less than the previous test. This difference is due to the great hardness of the tungsten carbide pin. The effect of hardness on the samples' weight loss in different duty cycles for deposition process has been observed here apparently.

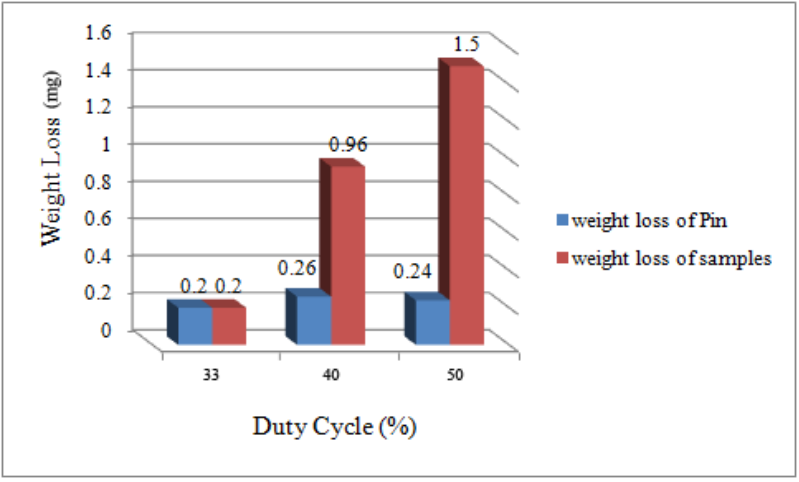

Figure 5: The Weight loss of TiN coatings for various duty cycles deposited on the H13 at a deposition temperature of $475^{\circ} \mathrm{C}$.

Indeed, the weight loss for deposited sample in $50 \%$ duty cycle was about 8 times of the parameter for sample with $33 \%$ duty cycle which is a sign of its superior wear. Of course, high surface roughness of a sample during $50 \%$ duty cycle can be a good reason for their higher weight loss. Because when the hard tungsten carbide pin moves on the sample, scratching of the peaks will be very probable. As can be seen from Figure 4 when duty cycles last longer, uneven surface roughness will increase. So we will have much weight loss when these peaks are higher and have more quantity [13]. This amount of weight loss has been shown in Figure 5 clearly for different duty cycles.

\subsection{The effect of deposition temperature}

Friction coefficient curves of the samples deposited at 475,500 and $525^{\circ} \mathrm{C}$ after wearing against steel pin using $10 \mathrm{~N}$ load on the pin are depicted in Figure 6.
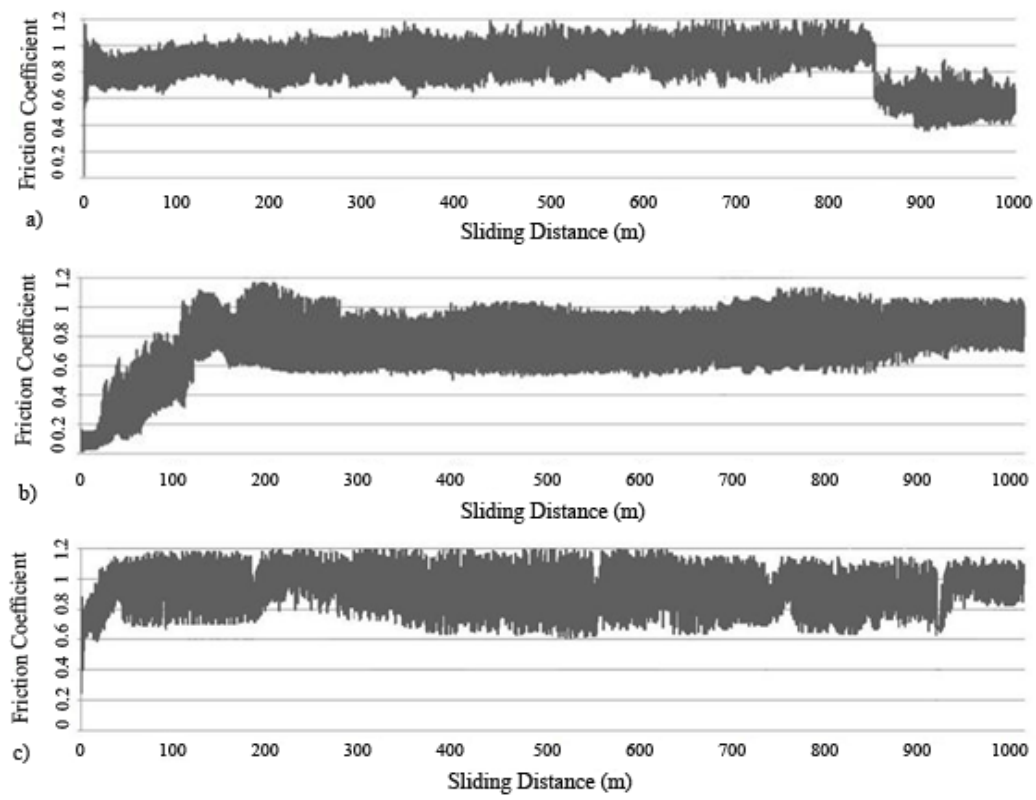

Figure 6: Friction coefficient diagrams of the deposited samples in a $33 \%$ duty cycle and temperatures of (a) $475^{\circ} \mathrm{C}$, (b) $500^{\circ} \mathrm{C}$, and (c) $525^{\circ} \mathrm{C}$ against a steel pins. 
As can be seen, the friction coefficient was almost same for 500 and $525^{\circ} \mathrm{C}$ having values of 0.8 to 1 which holds true for $475^{\circ} \mathrm{C}$ up to $800 \mathrm{~m}$ but decreases by 0.3 at the end of the path. In order to justify this phenomenon, we need to mention some points about TiN's wear behaviour the most important of which is high probability of rutile ( $\mathrm{TiO} 2)$ formation during the wear process.

Other researchers have declared the reason of low TiN's friction coefficient as being rutile formation like a layer on the sample or pin during the wear process $[8,10]$. It can be studied under the topic of reactivity of TiN. Rutile act as a plasticizer because of its low shear resistance, so when formed, it decreases the friction coefficient [13]. Different researches based on TiN deposition technique have proposed various equations for the formation of $\mathrm{TiO} 2$ phase. The formation energy related to each one of these reactions is different and each one demands its own special conditions.

Deposition of TiN through PACVD includes different compositions such as TiNxCly in the layer. TiNxCly which is not a stoichiometric compound can reach stability by subsequent reactions. Since moisture and oxygen are available during wearing, the reactions of TiNxCly will be possible [8]. The formation of rutile from TiNxCly is proposed as following [13]:

$$
\left.\begin{array}{l}
2 \mathrm{TiN}_{\mathrm{x}} \mathrm{Cl}_{\mathrm{y}}+3 \mathrm{H}_{2} \mathrm{O}=\mathrm{Ti}_{2} \mathrm{O}_{3}+3 \mathrm{HCl}+\mathrm{NH}_{3} \\
\mathrm{Ti}_{2} \mathrm{O}_{3}+1 / 2 \mathrm{O}_{2}=2 \mathrm{TiO}_{2}
\end{array}\right\} \mathrm{TiN}_{\mathrm{x}} \mathrm{Cl}_{\mathrm{y}}+3 \mathrm{H}_{2} \mathrm{O}+1 / 2 \mathrm{O}_{2}=2 \mathrm{TiO}_{2}+3 \mathrm{HCl}+\mathrm{NH}_{3}
$$

Existence of moisture, oxygen and chlorine is essential for this reaction. Because oxygen and moisture is available adequately in the atmosphere, we can mention chlorine as the key factor controlling the reaction. However, supplying the sufficient energy is another factor which shouldn't be disregarded [8]. Providing the required energy and existence of excessive chlorine in the structure of TiN, causes the surface to be changed chemically upon contact between coat and pin during the wear process. This newly formed material is the so-called rutile which is produced in little amounts on the wear surface. This thin layer of $\mathrm{TiO} 2$ which is called "transfer layer", reduces the contact between the steel pin and the sample coated with TiN as well as the friction coefficient of coating significantly. During wearing process by steel pin, some local adhesions can also be seen between the two surfaces. When no transfer layer is available on the surface or some other transitional phases such as iron oxides-which have high shear strength-form on the surface [15], significant force is needed to separate pin from sample and maintaining its movement which will ultimately lead to higher friction coefficients. Whereas the $\mathrm{TiO} 2$ as a ceramic phase with high hardness value and low shear strength when forms on the wearing surfaces, the friction coefficient will be decreased because of the little scraping and adhesion between surfaces as well as easy shearing in order to keep the movement of pin on sample.

In Figure 7 the friction coefficient diagrams of deposited samples at 475,500 and $525^{\circ} \mathrm{C}$ are shown after being worn against the tungsten carbide pins. 

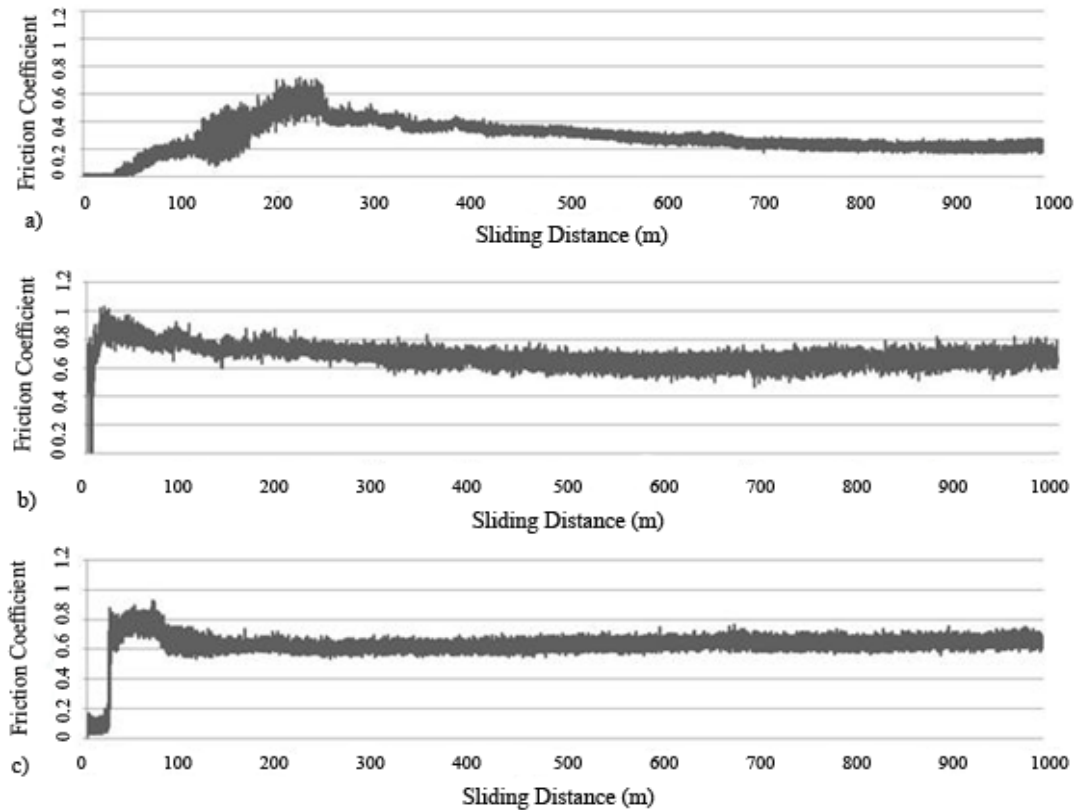

Figure 7: Friction coefficient diagrams of the deposited samples in a $33 \%$ duty cycle and temperatures of (a) $475^{\circ} \mathrm{C}$, (b) $500^{\circ} \mathrm{C}$, and (c) $525^{\circ} \mathrm{C}$ against tungsten carbide pins.

As evident from the pictures, the friction coefficient for high temperatures is approximately $0.6-0.7$ which is less in comparison with values obtained against the steel pin. This fact is attributed to their hardness values. One prominent point in this figure is seen in part (a) and that is the decline of friction coefficient up to 0.2. This observation is interpreted as follows: due to the low temperature of deposition in the sample, the internal content of chlorine was significantly high and especially higher than its solubility limit in the fcc network of TiN coating. Additionally, using the harder pin of tungsten carbide which applies much stress on the surface coating, higher energy will be provided for releasing the super saturated chlorine in the TiN network. Its results will be the formation of a solid self-lubricant layer on the surface and reduction in the friction coefficient [15]. Therefore, TiN can be classified as the low friction coatings here. We have also discussed differences due to change in the pin's material in previous sections.

Figure 8 shows the weight loss of the deposited samples and their related steel abrasive pins for 475 , 500 and $525^{\circ} \mathrm{C}$ temperatures. In studying this diagram, the weight loss of the disk samples and their related abrasive pins is utterly obvious for $525^{\circ} \mathrm{C}$ deposition temperature, although this difference is significantly less for lower temperatures, which is attributed to the hardness content of sample surface. In lower temperatures, smaller hardness values cause more wear and weight loss. The reason of severe weight loss for $475^{\circ} \mathrm{C}$ sample in comparison with zero weight loss for 525 samples, regardless of the hardness theory, is also justified by weight gain due to the gripping of pin chips in worn grooves for $525^{\circ} \mathrm{C}$ sample. Decrease in hardness of the sample affects the weight loss of its abrasive pin and reduces it. Noteworthy here is the difference for the parameters of sample weight loss and friction coefficient in the optimum condition. Indeed, in order to obtain the lowest friction coefficient, we were ought to choose the lowest temperature of deposition $\left(475^{\circ} \mathrm{C}\right)$, meanwhile the least weight loss is acquired after wearing the deposited samples at highest temperature $\left(525^{\circ} \mathrm{C}\right)$. 


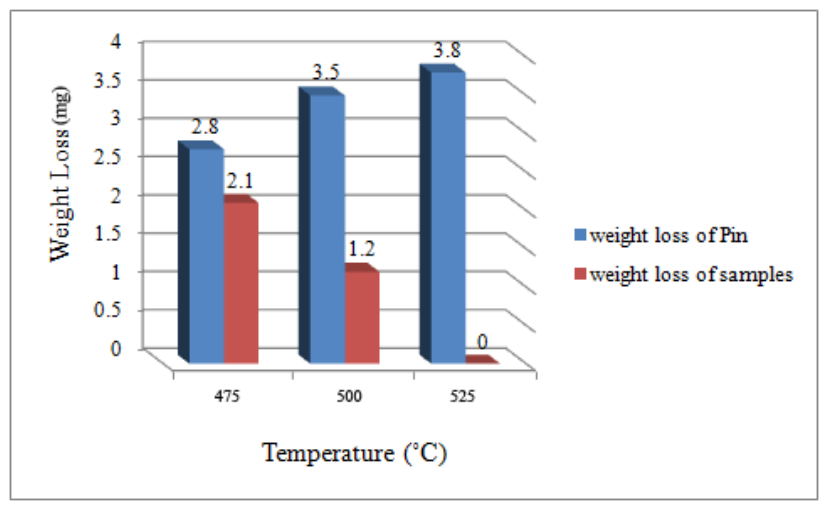

Figure 8: Weight loss of the deposited samples in a 33\% duty cycle and their respective steel abrasive pins for 475,500 , and $525^{\circ} \mathrm{C}$ temperatures.

Figure 9 summarizes weight loss values of the deposited samples for 475,500 and $525^{\circ} \mathrm{C}$ and their related abrasive tungsten carbide pins. As also can be seen from these values, the deposited sample at $525^{\circ} \mathrm{C}$ has shown much less weight loss, which is mainly because of its high hardness values. Noteworthy here is that the weight loss variations of abrasive pins have been completely inconsiderable. It can be concluded that the variation of hardness for samples deposited at different temperatures, has been inconsiderable compared to the hardness of their abrasive pins, so have not had remarkable influence on the weight loss of pins.

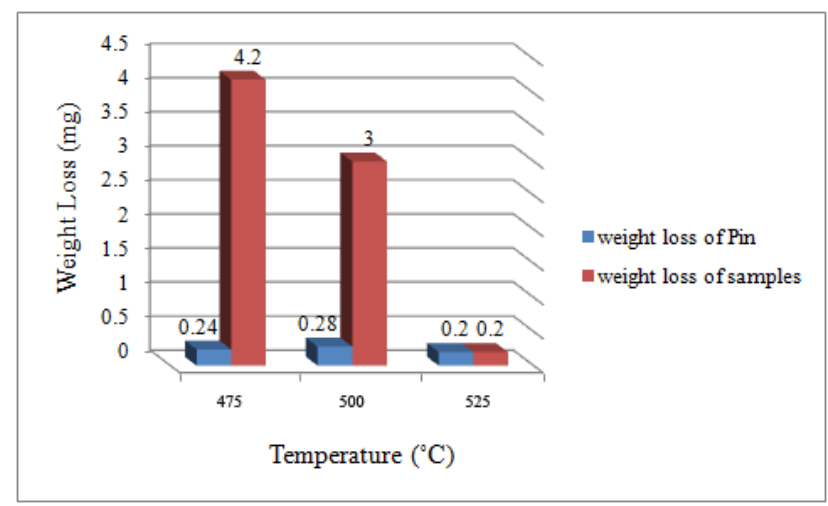

Figure 9: Weight loss values of the deposited samples for 475,500 , and $525^{\circ} \mathrm{C}$ and their respective abrasive tungsten carbide pins.

\section{CONCLUSIONS}

Studying the wear behavior of TiN nano-structured coating on substrate plasma nitrided steel lead to the following conclusions:

1. Creating a diffusion layer of nitrogen and TiN coating due to its high hardness and less friction and adherence between two metallic and ceramic surfaces may cause higher wear resistance.

2. Increasing the temperature of TiN deposition procedure from 475 to $525^{\circ} \mathrm{C}$ will lead to lower weight loss from 2.1 to $0 \mathrm{mg}$ for steel pins and from 4.2 to $0.2 \mathrm{mg}$ for tungsten carbide pins because of higher hardness values, meanwhile, it raises the coefficient of friction against steel and WC pins.

3. Increasing the duty cycle of the TiN deposition process from 33 to $50 \%$ will contribute to relative increase in weight loss values from 0 to $0.2 \mathrm{mg}$ for steel pins and from 0.2 to $1.5 \mathrm{mg}$ for tungsten carbide pins.

\section{BIBLIOGRAPHY}

[1] VERSHININ, N., FILONOV, K., STRAUMAL, B., et al., "Corrosion resistance of the vacuum arc deposited Ti, TiN and TiO2 coatings on large area glass substrates”, Surface and Coatings Technology, v. 125 , pp.223-228, 2000. 
[2] PFOHL, C., RIE, K.-T., HIRSCHFELD, M.K., et al., "Evaluation of the corrosion behaviour of wearresistant PACVD coatings", Surface and Coatings Technology, v.112, pp. 114-117, 1999.

[3] CHENG, H.-E., LEE, W.-J., HSU, C.-M., "The effect of deposition temperature on the properties of TiN diffusion barriers prepared by atomic layer chemical vapor deposition", Thin Solid Films, v.485, pp. 59-65, 2005.

[4] KLIMEK, K.S., AHN, H., SEEBACH, I., et al., "Duplex process applied for die-casting and forging tools", Surface and Coatings Technology, v.174-175, pp.677-680, 2003.

[5] STOIBER, M., BADISCH, E., LUGMAIR, C., et al., "Low-friction TiN coatings deposited by PACVD", Surface and Coatings Technology, v.163-164, pp.451-456, 2003.

[6] KAWATA, K., SUGIMURA, H., TAKAI, O., "Effects of chlorine on tribological properties of TiN films prepared by pulsed DC plasma-enhanced chemical vapor deposition", Thin Solid Films, v. 407, pp.38-44, 2002.

[7] MITTERER, C., HOLLER, F., REITBERGER, D., et al., "Industrial applications of PACVD hard coatings", Surface and Coatings Technology, v. 163-164, pp.716-722, 2003.

[8] BADISCH, E., MITTERER, C., MAYRHOFER, P.H., et al., "Characterization of tribo-layers on selflubricating PACVD TiN coatings", Thin solid film, v.460, pp.125-132, 2004.

[9] RAOUFI, M., MIRDAMADI, SH., MAHBOUBI, F., "Correlation between the surface characteristics and the duty cycle for the PACVD-derived TiN nanostructured films", Surface \& Coatings Technology, v. 205, pp. 4980-4984, 2011.

[10] HOLMBERG, K., MATTHEWS, A., Coating Tribology: Properties, Mechanisms, Techniques and Applications in Surface Engineering, Elsevier, 1994.

[11] TANNO, Y., AZUSHIMA, A, "Effect of counter materials on coefficients of friction of TiN coatings with preferre d grain orientations", Wear, v.266, 2009.

[12] STACHOWIAK, G., Wear, materials, mechanisms and practice, John Wiley, 2006.

[13] BADISCH, E., STOIBER, M., FONTALVO, G. A., et al., "Low-friction PACVD TiN coating: influence of $\mathrm{Cl}$ content and testing condition on the tribological properties", Surface and Coatings Technology, v.174-175, pp.450-454, 2003.

[14] FATEH, N., FONTALVO, G. A., GASSNER, G., et al., "Influence of high-temperature oxide formation on the tribological behaviour of TiN and VN coatings", Wear, v.262, n.9-10, 2007.

[15] BADISCH, E., FONTALVO, G.A., MITTERER, C., "The response of PACVD TiN coatings to tribological tests with different counterparts", Wear, v.256, n.1-2, 2004. 